\title{
Effect of constant temperature on development and survival of Lymantria albescens Hori and Umeno and Lymantria xylina Swinhoe (Lepidoptera: Lymantriinae) from Okinawa, Japan
}

\author{
Hideharu Tsukagoshi ${ }^{* \dagger}$ and Yasutomo Higashiura \\ Laboratory of Ecology, Tokyo University of Pharmacy \& Life Sciences; Hachioji, Tokyo 192-0392, Japan \\ (Received 18 November 2008; Accepted 8 May 2009)
}

\begin{abstract}
We investigated the effect of temperature on the developmental and survival rates in the life stages of the Okinawan gypsy moth, Lymantria albescens, and the casuarina tussock moth L. xylina, from Okinawa, Japan. Under laboratory conditions at constant temperatures of $17.5,20.0,22.5,25.0,27.5$ and $30.0^{\circ} \mathrm{C}$, the thermal threshold and thermal constant from larva to adult for $L$. albescens and L. xylina were 9.1-9.9 and $8.4-11.0^{\circ} \mathrm{C}$ and $780.8-872.2$ and 731.8-1,053.8 degree-days, respectively. Last-instar larvae of males of both species were mostly 6th instars, whereas a large number of female last-instar larvae were 6th and 7th instars. Survival rates of L. albescens and L. xylina were very low at $30.0^{\circ} \mathrm{C}$, indicating that these species in Okinawa are not resistant to temperatures higher than $30^{\circ} \mathrm{C}$. Our results provide information for predicting the appearance of field populations of L. albescens and L. xylina in Okinawa.
\end{abstract}

Key words: Okinawan gypsy moth; casuarinas tussock moth; degree-days; developmental zero; mortality

\section{INTRODUCTION}

The Okinawan gypsy moth, Lymantria albescens Hori and Umeno (Lepidoptera: Lymantriinae), is distributed in the Ryukyu Islands of Japan, including Ishigaki and Okinawa (Inoue, 1982; Pogue and Schaefer, 2007). Lymantria albescens was recorded as a pest of Eucalyptus camaldulensis, Macaranga tanarius, Castanopsis seiboldii, and Elaeocarpus sylvestris (Nasu et al., 2004; Tominaga, 2004; Pogue and Schaefer, 2007).

The Casuarina tussock moth, L. xylina Swinhoe (Lepidoptera: Lymantriinae), is distributed in southern Japan, Taiwan, and China (Fujian, Guangdong) (Inoue, 1982; Pogue and Schaefer, 2007). In Japan, it is distributed in Shikoku, Kyushu and Okinawa (Inoue, 1982), and also in Yamaguchi prefecture in Honshu, Japan (Jinbo, 2001). The Casuarina tussock moth is a forest tree defoliator in Taiwan (Chang, 1991), especially in casuarina ( $\mathrm{Ca}$ suarina equisetifolia) and acacia (Acacia confusa) forests, and fruit tree orchards (Chao et al., 1996). Sixty-three species of plants belonging to 29 families were recorded as the host plants of L. xylina in Taiwan (Chao et al., 1996). The host plants of $L$. xylina in Japan are not yet well known but likely consist of a wide range of species in many families.

It is important to predict life history events in these species for forest and fruit tree management; however, there have been no studies on the thermal constant and thermal threshold for these Okinawan species. Therefore, this paper presents the effect of temperature on the development and survival of $L$. albescens and L. xylina collected in Naha, Okinawa, and reared under laboratory conditions at six constant temperatures. We also provide information on the numbers of larval instars.

\section{MATERIALS AND METHODS}

Insects. Egg masses of $L$. albescens and $L$.

\footnotetext{
* To whom correspondence should be addressed at: E-mail: hide.tsuka@fish.hokudai.ac.jp

${ }^{\dagger}$ Present address: Graduate School of Fisheries Science, Hokkaido University, Hakodate, Hokkaido 041-8611, Japan. DOI: 10.1303/aez.2009.491
} 
xylina were collected in Naha city, Okinawa, Japan $\left(26^{\circ} 22^{\prime} \mathrm{N}, 127^{\circ} 71^{\prime} \mathrm{E}\right)$ in late February, 2006 and 2007. Nearly all egg masses of $L$. albescens and $L$. xylina were collected on aerial roots of Ficus microcarpa in Okinawa. The collected egg masses were placed in Petri dishes, and kept at $20^{\circ} \mathrm{C}$ in incubators (SANYO, Osaka: MIR-253). We began rearing experiments using hatched larvae less than $24 \mathrm{~h}$ old.

Rearing methods for development and survival at different temperatures. We conducted rearing experiments of larval and pupal stages in incubators set at 17.5, 20.0, 22.5, 25.0, 27.5 and $30.0^{\circ} \mathrm{C}$ with a long-day photoperiod (16L8D). Humidity levels of $80 \%$ were maintained by placing two containers of water at the bottom of each incubator. We used the artificial diet of Bio-Serv (Frenchtown, NJ, USA: product \# F9642B) for larval rearing. We dispensed about $80 \mathrm{ml}$ of the diet into plastic containers (Sweetheart, Chicago, IL, US: ME6RX, 6oz) with paper lids, and reared seven larvae in each container upside-down with the diet uppermost before 4th instar. After the 3rd instar, the larvae were placed individually in paper containers (Dixie Japan, Tokyo: GHCM06WN, $6 \mathrm{oz}$ ) with plastic lids in which 15 small holes provided ventilation. We filled plastic cups (FP CHUPA, Tokyo: CP070004, 1/2 oz) with the diet, and placed two cups in each paper container. The diet was replaced at regular intervals $(2 \mathrm{~d}$ at 27.5 and $30.0^{\circ} \mathrm{C}, 3 \mathrm{~d}$ at 22.5 and $25.0^{\circ} \mathrm{C}$, and $4 \mathrm{~d}$ at 20 and $17.5^{\circ} \mathrm{C}$ ). We checked the survival, larval molt, pupation and adult emergence daily. Failures in larval and pupal molting, and dead larvae and pupae were not included in calculations of the thermal threshold and thermal constant in this study.

The developmental rates $Y$ (measured as $1 /$ (developmental period in days)) of various life stages (i.e., larva, pupa, and total development) were fitted to temperatures to obtain the relationship in terms of $Y=a T+b$, where $T$ is temperature, and $a$ and $b$ are regression parameters. The thermal threshold $\left(T_{0}=-b / a\right)$ and thermal constant $(K=1 / a)$ were obtained from the regression lines.

The developmental period and survival rate in each stage were compared among temperatures. Data on the developmental period was subjected to ANOVA followed by Tukey-Kramer's multiple comparison test. Data on the survival rates were subjected to the chi-square test.

\section{RESULTS}

\section{L. albescens}

The number of larval molts in L. albescens (Table 1) showed that the last larval instars were 5th, 6th and 7th instars in males, and 5th, 6th, 7th, and 8th instars in females. A large part of the lastinstars were 6th instar $(84.6 \%)$ in males, and 6th and 7 th instars (62.9\% and $34.8 \%$, respectively) in females.

The survival rate at immature stages (1st-instar larvae to adults) of $L$. albescens (Table 2) was significantly different at different temperatures $\left(\chi^{2}=43.41 ; \mathrm{df}=5 ; p<0.0001\right)$, and was lowest at $30.0^{\circ} \mathrm{C}$. In 6 th instar larvae and pupae of L. albescens, survival was significantly different at different temperatures (6th instar: $\chi^{2}=31.38$; $\mathrm{df}=5 ; \quad p<0.0001$, pupa: $\chi^{2}=32.66 ; \quad \mathrm{df}=5 ; p<$ 0.0001 ), and was lowest at $30.0^{\circ} \mathrm{C}$. Examination of survival rates at each developmental stage revealed that the higher mortality at $30.0^{\circ} \mathrm{C}$ was largely attributable to the death of 1st and 6th instar larvae and pupae, with survival dropping below $80 \%$ for these three developmental stages. Survival of other instar larvae was generally high.

The developmental periods of $L$. albescens at different temperatures (Table 3 ) decreased as temperatures increased from $17.5^{\circ} \mathrm{C}$ to $27.5^{\circ} \mathrm{C}$.

Table 4 shows the regression equations for the developmental period against temperatures, values of thermal thresholds and thermal constants calculated for L. albescens using data from $17.5^{\circ} \mathrm{C}$ to $27.5^{\circ} \mathrm{C}$ (excluding data at $30^{\circ} \mathrm{C}$ ). Although the last-

Table 1. Numbers of last-instar larvae of Lymantria albescens and L. xylina from Okinawa in laboratory rearings

\begin{tabular}{lllll}
\hline & \multicolumn{5}{c}{ Number of last-instar larva (\%) } \\
\cline { 2 - 5 } & 5th instar & 6th instar & 7 th instar & 8 th instar \\
\hline $\begin{array}{l}\text { L. albescens } \\
\text { Male }\end{array}$ & $8(6.8)$ & $99(84.6)$ & $10(8.5)$ & - \\
Female & $1(1.1)$ & $56(62.9)$ & $31(34.8)$ & $1(1.1)$ \\
$\begin{array}{l}\text { L. xylina } \\
\text { Male }\end{array}$ & $8(11.4)$ & $54(77.1)$ & $8(11.4)$ & - \\
Female & $1(1.1)$ & $36(41.4)$ & $46(52.9)$ & $4(4.6)$ \\
\hline
\end{tabular}

Number of larva with each instar as the last-instar.

Numbers in parentheses indicate the percentage of larvae in each last-instar. 
Table 2. Survival rates of larvae and pupae of Lymantria albescens and L. xylina collected from Okinawa reared at different temperatures

\begin{tabular}{|c|c|c|c|c|c|c|c|c|c|}
\hline \multirow{2}{*}{$\begin{array}{c}\text { Temperature } \\
\left({ }^{\circ} \mathrm{C}\right)\end{array}$} & \multicolumn{9}{|c|}{ Survival (\%) } \\
\hline & 1 st instar & 2nd instar & 3rd instar & 4th instar & 5th instar & 6th instar & 7th instar & Pupa & Larva-adult \\
\hline \multicolumn{10}{|l|}{ L. albescens } \\
\hline 17.5 & $31(88.6)$ & $31(100)$ & $31(100)$ & $31(100)$ & $31(100)$ & $30(100)$ & $11(100)$ & $30(96.8)$ & $30(85.7)$ \\
\hline 20.0 & 35 (94.6) & $34(97.1)$ & $33(97.1)$ & $33(100)$ & $32(97.0)$ & $32(100)$ & $9(90.0)$ & $29(93.5)$ & $29(78.4)$ \\
\hline 22.5 & $64(94.1)$ & $64(100)$ & 63 (98.4) & $61(96.8)$ & $59(96.7)$ & $55(100)$ & $9(100)$ & $59(100)$ & $59(86.8)$ \\
\hline 25.0 & $58(87.9)$ & $58(100)$ & $57(98.3)$ & $55(96.5)$ & $54(98.2)$ & $51(98.1)$ & $13(100)$ & $52(98.1)$ & $52(78.8)$ \\
\hline 27.5 & $38(88.4)$ & $38(100)$ & $37(97.4)$ & $36(97.3)$ & $34(94.4)$ & $30(93.8)$ & $4(100)$ & $30(93.8)$ & $30(69.8)$ \\
\hline 30.0 & $19(76.0)$ & $19(100)$ & $19(100)$ & $17(89.5)$ & $15(88.2)$ & $11(73.3)$ & $6(85.7)$ & $6(60.0)$ & $6(24.0)$ \\
\hline \multicolumn{10}{|l|}{ L. xylina } \\
\hline 17.5 & $36(97.3)$ & $36(100)$ & $35(97.2)$ & $34(97.1)$ & $34(100)$ & $34(100)$ & $13(92.9)$ & $30(90.9)$ & $30(81.1)$ \\
\hline 20.0 & 35 (97.2) & $34(97.1)$ & $33(97.1)$ & $33(100)$ & $32(97.0)$ & $32(100)$ & $23(95.8)$ & $28(90.3)$ & $28(77.8)$ \\
\hline 22.5 & $54(100)$ & $52(96.3)$ & $50(96.2)$ & $49(98.0)$ & $49(100)$ & $45(93.8)$ & $19(95.0)$ & $41(91.1)$ & $41(75.9)$ \\
\hline 25.0 & $61(100)$ & $57(93.4)$ & $57(100)$ & $54(94.7)$ & $54(100)$ & $46(90.2)$ & $23(95.8)$ & $38(79.2)$ & $38(62.3)$ \\
\hline 27.5 & $20(100)$ & $20(100)$ & $20(100)$ & $20(100)$ & $20(100)$ & $15(100)$ & $1(100)$ & $19(95.0)$ & $19(95.0)$ \\
\hline 30.0 & $17(73.9)$ & $17(100)$ & $15(88.2)$ & $15(100)$ & $14(93.3)$ & $9(64.3)$ & $8(100)$ & $1(11.1)$ & $1(4.3)$ \\
\hline
\end{tabular}

Numbers in parentheses indicate the percentage of larvae that survived in each instar.

Survival of 8th instar larvae was $100 \%$ : one larva at $25^{\circ} \mathrm{C}$ in $L$. albescens, and three larvae at $22.5^{\circ} \mathrm{C}$ and one larva at $20^{\circ} \mathrm{C}$ in $L$. xylina.

Table 3. Developmental periods of larvae and pupae of Lymantria albescens and L. xylina collected from Okinawa at different temperature

\begin{tabular}{|c|c|c|c|c|c|c|c|c|c|c|c|c|}
\hline \multirow{3}{*}{$\begin{array}{c}\text { Temperature } \\
\left({ }^{\circ} \mathrm{C}\right)\end{array}$} & \multicolumn{12}{|c|}{ Developmental period in days (mean \pm SD) } \\
\hline & \multicolumn{4}{|c|}{ Male } & \multicolumn{4}{|c|}{ Female (6th instar) } & \multicolumn{4}{|c|}{ Female (7th instar) } \\
\hline & $n$ & Larva & Pupa & Larva-adult & $n$ & Larva & Pupa & Larva-adult & $n$ & Larva & Pupa & Larva-adult \\
\hline \multicolumn{13}{|l|}{ L. albescens } \\
\hline 17.5 & 14 & $79.3 \pm 4.4 \mathrm{a}$ & $30.9 \pm 1.2 \mathrm{a}$ & $110.2 \pm 5.0 \mathrm{a}$ & 5 & $82.4 \pm 2.9 \mathrm{a}$ & $29.2 \pm 0.8 \mathrm{a}$ & $111.6 \pm 2.2 \mathrm{a}$ & 9 & $91.8 \pm 3.6 \mathrm{a}$ & $28.4 \pm 1.1 \mathrm{a}$ & $120.2 \pm 3.1 \mathrm{a}$ \\
\hline 20.0 & 13 & $53.2 \pm 5.2 \mathrm{~b}$ & $20.0 \pm 1.4 b$ & $73.2 \pm 4.8 \mathrm{~b}$ & 9 & $57.4 \pm 3.1 \mathrm{~b}$ & $18.1 \pm 1.5 b$ & $75.5 \pm 5.4 b$ & 6 & $61.6 \pm 2.7 b$ & $17.5 \pm 0.7 b$ & $79.2 \pm 2.2 \mathrm{~b}$ \\
\hline 22.5 & 28 & $44.7 \pm 2.9 \mathrm{c}$ & $16.2 \pm 1.0 \mathrm{c}$ & $60.9 \pm 2.6 \mathrm{c}$ & 18 & $45.6 \pm 3.1 \mathrm{c}$ & $14.3 \pm 1.5 \mathrm{c}$ & $59.9 \pm 2.6 \mathrm{c}$ & 7 & $56.4 \pm 6.5 \mathrm{c}$ & $14.1 \pm 1.1 \mathrm{c}$ & $70.5 \pm 6.7 \mathrm{c}$ \\
\hline 25.0 & 27 & $39.3 \pm 3.1 \mathrm{~d}$ & $13.7 \pm 0.7 \mathrm{~d}$ & $53.0 \pm 3.0 \mathrm{~d}$ & 11 & $40.7 \pm 2.8 \mathrm{~d}$ & $11.8 \pm 0.6 \mathrm{~d}$ & $52.5 \pm 2.7 \mathrm{~d}$ & 7 & $47.1 \pm 7.4 \mathrm{~d}$ & $11.8 \pm 1.1 \mathrm{~d}$ & $58.9 \pm 2.6 \mathrm{~d}$ \\
\hline 27.5 & 14 & $33.0 \pm 3.5 \mathrm{e}$ & $11.4 \pm 1.0 \mathrm{e}$ & $44.5 \pm 4.1 \mathrm{e}$ & 12 & $36.1 \pm 2.8 \mathrm{e}$ & $9.8 \pm 0.7 \mathrm{e}$ & $46.0 \pm 2.8 \mathrm{e}$ & 1 & $39.0 \mathrm{~d}$ & $9.0 \mathrm{~d}$ & $48.0 \mathrm{~d}$ \\
\hline 30.0 & 3 & $31.0 \pm 0.0 \mathrm{e}$ & $10.0 \pm 0.0 \mathrm{e}$ & $41.0 \pm 0.0 \mathrm{e}$ & 1 & $32.5 \mathrm{de}$ & $10.5 \mathrm{de}$ & $43.0 \mathrm{de}$ & 1 & $39.0 \mathrm{~d}$ & $9.5 \mathrm{~d}$ & $46.5 \mathrm{~d}$ \\
\hline \multicolumn{13}{|l|}{ L. xylina } \\
\hline 17.5 & 15 & $86.3 \pm 5.5 \mathrm{a}$ & $29.4 \pm 1.7 \mathrm{a}$ & $115.7 \pm 5.6 \mathrm{a}$ & 5 & $84.8 \pm 3.5 \mathrm{a}$ & $27.2 \pm 0.8 \mathrm{a}$ & $112.0 \pm 3.4 \mathrm{a}$ & 10 & $95.9 \pm 4.0 \mathrm{a}$ & $25.4 \pm 0.8 \mathrm{a}$ & $121.3 \pm 3.9 \mathrm{a}$ \\
\hline 20.0 & 6 & $60.6 \pm 3.2 \mathrm{~b}$ & $18.1 \pm 1.0 \mathrm{~b}$ & $78.7 \pm 3.6 b$ & 2 & $58.3 \pm 3.9 \mathrm{~b}$ & $15.5 \pm 0.7 \mathrm{~b}$ & $73.8 \pm 3.2 \mathrm{~b}$ & 17 & $71.6 \pm 3.5 \mathrm{~b}$ & $16.6 \pm 1.1 \mathrm{~b}$ & $88.2 \pm 3.6 \mathrm{~b}$ \\
\hline 22.5 & 16 & $45.8 \pm 3.7 \mathrm{c}$ & $15.6 \pm 0.9 \mathrm{c}$ & $61.4 \pm 3.7 \mathrm{c}$ & 9 & $49.2 \pm 5.6 \mathrm{c}$ & $13.7 \pm 0.8 \mathrm{bc}$ & $62.9 \pm 5.3 \mathrm{c}$ & 10 & $60.9 \pm 4.5 \mathrm{c}$ & $13.6 \pm 0.7 \mathrm{c}$ & $74.5 \pm 4.4 \mathrm{c}$ \\
\hline 25.0 & 14 & $41.8 \pm 4.2 \mathrm{~cd}$ & $12.7 \pm 0.8 \mathrm{~d}$ & $54.5 \pm 3.9 \mathrm{~d}$ & 8 & $37.9 \pm 3.1 \mathrm{~d}$ & $12.1 \pm 2.0 \mathrm{~cd}$ & $50.0 \pm 2.4 \mathrm{~d}$ & 9 & $53.9 \pm 2.7 \mathrm{~d}$ & $10.7 \pm 0.9 \mathrm{~d}$ & $64.6 \pm 2.6 \mathrm{~d}$ \\
\hline 27.5 & 2 & $30.0 \pm 3.5 \mathrm{e}$ & $12.3 \pm 0.4 \mathrm{~d}$ & $42.3 \pm 3.2 \mathrm{e}$ & 12 & $34.2 \pm 2.2 \mathrm{~d}$ & $10.8 \pm 0.9 \mathrm{~d}$ & $45.0 \pm 2.0 \mathrm{e}$ & & - & - & - \\
\hline 30.0 & 1 & $38.0 \mathrm{de}$ & $11.0 \mathrm{~d}$ & $49.0 \mathrm{cde}$ & & - & - & - & & - & - & - \\
\hline
\end{tabular}

Values followed by different letters in the same column are significantly different (Tukey-Kramer test, $p<0.05$ ).

instar was 6th instar in almost all males (85\%), 6th and 7 th instars as the last-instar were $63 \%$ and $35 \%$ in females, respectively. Female values for 6 th and 7th last-instars are shown separately. The thermal threshold (Table 4) for male larvae was estimated to be $9.4^{\circ} \mathrm{C}$, that for male pupae was $11.0^{\circ} \mathrm{C}$, and for female larvae with 6 th and 7 th instars as the last-instar it was 8.1 and $9.1^{\circ} \mathrm{C}$, respectively. For female pupae with 6 th and 7 th instars as the lastinstar it was 11.7 and $12.2^{\circ} \mathrm{C}$, respectively. The 
Table 4. Regression equation of developmental period, thermal threshold and thermal constant for Lymantria albescens and L. xylina

\begin{tabular}{|c|c|c|c|c|}
\hline & Regression equation & $r^{2}$ & $\begin{array}{c}\text { Thermal } \\
\text { threshold }\left({ }^{\circ} \mathrm{C}\right)\end{array}$ & $\begin{array}{c}\text { Thermal constant } \\
\text { (degree-days) }\end{array}$ \\
\hline \multicolumn{5}{|l|}{ L. albescens } \\
\hline \multicolumn{5}{|l|}{ Male } \\
\hline Larva & $Y=-0.01581+0.00168 T$ & 0.880 & 9.4 & 594.8 \\
\hline Pupa & $Y=-0.05891+0.00533 T$ & 0.924 & 11.0 & 187.6 \\
\hline Larva-adult & $Y=-0.01267+0.00128 T$ & 0.925 & 9.9 & 780.8 \\
\hline \multicolumn{5}{|c|}{ Female (6th instar) } \\
\hline Larva & $Y=-0.01187+0.00147 T$ & 0.869 & 8.1 & 681.9 \\
\hline Pupa & $Y=-0.07603+0.00648 T$ & 0.899 & 11.7 & 154.2 \\
\hline Larva-adult & $Y=-0.01106+0.00121 T$ & 0.928 & 9.1 & 826.5 \\
\hline \multicolumn{5}{|c|}{ Female (7th instar) } \\
\hline Larva & $Y=-0.01232+0.00136 T$ & 0.903 & 9.1 & 736.5 \\
\hline Pupa & $Y=-0.08313+0.00684 T$ & 0.942 & 12.2 & 146.2 \\
\hline Larva-adult & $Y=-0.01134+0.00115 T$ & 0.939 & 9.9 & 872.2 \\
\hline \multicolumn{5}{|l|}{ L. xylina } \\
\hline \multicolumn{5}{|l|}{ Male } \\
\hline Larva & $Y=-0.02019+0.00183 T$ & 0.882 & 11.0 & 546.2 \\
\hline Pupa & $Y=-0.06145+0.00558 T$ & 0.937 & 11.0 & 179.3 \\
\hline Larva-adult & $Y=-0.01499+0.00137 T$ & 0.936 & 11.0 & 731.8 \\
\hline \multicolumn{5}{|c|}{ Female (6th instar) } \\
\hline Larva & $Y=-0.01886+0.00177 T$ & 0.917 & 10.7 & 565.2 \\
\hline Pupa & $Y=-0.04939+0.00529 T$ & 0.830 & 9.3 & 189.1 \\
\hline Larva-adult & $Y=-0.01371+0.00132 T$ & 0.951 & 10.4 & 756.3 \\
\hline \multicolumn{5}{|c|}{ Female (7th instar) } \\
\hline Larva & $Y=-0.00783+0.00107 T$ & 0.906 & 7.3 & 932.4 \\
\hline Pupa & $Y=-0.08260+0.00706 T$ & 0.932 & 11.7 & 141.7 \\
\hline Larva-adult & $Y=-0.00795+0.00095 T$ & 0.942 & 8.4 & $1,053.8$ \\
\hline
\end{tabular}

Regression equations calculated based on the values obtained at temperatures from 17.5 to $27.5^{\circ} \mathrm{C}$.

$Y$ and $T$ in regression equations show (1/developmental period in days) and temperatures $\left({ }^{\circ} \mathrm{C}\right)$, respectively.

thermal constants (Table 4) were 594.8 degree-days for male larvae, and 187.6 degree-days for male pupae. Female larvae with 6th and 7 th instars as the last-instar required 681.9 and 736.5 degreedays, respectively, while female pupae with 6 th and 7th instars as the last-instar needed 154.2 and 146.2 degree-days, respectively.

\section{L. xylina}

The number of larval molts in L. xylina (Table 1) was 5th, 6th and 7th instars in males, and 5th, 6th, 7th, and 8th instars in females. Most of the last-instars were 6th instar (77.1\%) in males, and 6th and 7 th instars $(41.4 \%$ and $52.9 \%$, respectively) in females.

The survival rate of the immature stages (1st instar larvae to adults) of L. xylina from Okinawa (Table 2) showed that the survival of 1st instar larvae to adults was significantly different at different temperatures $\left(\chi^{2}=56.46 ; \mathrm{df}=5 ; p<0.0001\right)$, being lowest at $30.0^{\circ} \mathrm{C}$. In $1 \mathrm{st}$ and 6 th instar larvae and pupae, survival was significantly different at different temperatures (1st instar: $\chi^{2}=40.17 ; \mathrm{df}=5$; $p<0.0001$; 6th instar: $\chi^{2}=25.47$; df $=5 ; p<0.0001$; pupa: $\chi^{2}=42.87$; $\mathrm{df}=5 ; p<0.0001$ ), and was lowest at $30.0^{\circ} \mathrm{C}$. The higher mortality at $30.0^{\circ} \mathrm{C}$ was largely attributable to the death of 1 st and 6 th instar larvae and pupae, with survival dropping below $75 \%$ for these three developmental stages. The survival of other instars was generally high (frequently about $90 \%$ ).

Developmental periods of L. xylina at different temperatures (Table 3) decreased as temperature increased from $17.5^{\circ} \mathrm{C}$ to $27.5^{\circ} \mathrm{C}$.

Table 4 shows the regression equations for the developmental period against temperatures, values of thermal thresholds and thermal constants calculated for L. xylina using data from $17.5^{\circ} \mathrm{C}$ to 
$27.5^{\circ} \mathrm{C}$ (excluding data for $30^{\circ} \mathrm{C}$ ). The last-instar was 6 th instar in more than $77 \%$ males, but in females, two types of last-instar were observed, 6th instar (41\%) and 7th instar (53\%). These values are shown for females for each type of last-instar. The thermal threshold for both larvae and male pupae was identical at $11.0^{\circ} \mathrm{C}$. The thermal thresholds for female larvae with 6 th and 7 th instars as the lastinstar were 10.7 and $7.3^{\circ} \mathrm{C}$, respectively, and for female pupae were 9.3 and $11.7^{\circ} \mathrm{C}$, respectively. The thermal constants required 546.2 degree-days for male larvae, and 179.3 degree-days for male pupae. Female larvae with 6th and 7 th instars as the last-instar required 565.2 and 932.4 degreedays, respectively, and female pupae 189.1 and 141.7 degree-days, respectively.

\section{DISCUSSION}

Regression analysis for developmental rates during larval and adult stages predicted a temperature threshold of $9.1-9.9^{\circ} \mathrm{C}$, and thermal constant of 780.8-872.2 degree-days for L. albescens. The corresponding values for L. xylina were $8.4-11.0^{\circ} \mathrm{C}$, and 731.8-1,053.8 degree-days. These values are similar for L. albescens and L. xylina collected in Okinawa, and indicate that both Okinawan species show similar physiological responses to temperature.

Furuta (1973) concluded that the thermal threshold of the female larval stage of Sapporo (Hokkaido) L. dispar was between 6.5 and $9.5^{\circ} \mathrm{C}$. Thermal thresholds of $L$. albescens, the most southern Lymantriinae in Japan, are within the range of those of larval stages in Hokkaido L. dispar, the most northern subspecies in Japan. Lymantria (P.) albescens hatches in early March (mean day temperature in March between 1999 and 2008 at Naha, Okinawa, Japan $=18.9^{\circ} \mathrm{C}$, calculated by using data on the web site of the Japan Meteorological Agency, http://www.data.jma.go.jp/obd/ stats/etrn/index.php), and emerges in early June (mean in June $=27.0^{\circ} \mathrm{C}$ ). On the other hand, Hokkaido L. dispar hatches in early May (mean in May at Sapporo, Hokkaido, Japan $=12.8^{\circ} \mathrm{C}$ ), and emerges in early August (mean in August= $22.5^{\circ} \mathrm{C}$ ). Although there are great differences in latitude (Naha: $26^{\circ} 12^{\prime} \mathrm{N}$, Sapporo: $43^{\circ} 3^{\prime} \mathrm{N}$ ), there was little difference in mean temperatures during the developmental periods between species. These differences in developmental periods indicate that both species have evolved so as to hatch and emerge at similar and optimal temperatures in different respective regions.

Kiritani (1997) reported that the thermal threshold from egg to adult for 83 Lepidopteran species was $10.4 \pm 2.4^{\circ} \mathrm{C}$ (mean $\pm \mathrm{SD}$ ), and the thermal constant for 80 Lepidopteran species was $463.3 \pm$ 153.5 degree-days. The thermal thresholds of $L$. albescens and L. xylina of Okinawa estimated in the present study were within the range for the 83 Lepidopteran species, but our estimate of the thermal constants was higher than that for the 80 Lepidopteran species. The development of $L$. albescens and L. xylina in Okinawa requires a greater period at the effective temperature, because both species are among the largest Lepidoptera reported by $\mathrm{Ki}$ ritani (1997).

In larva-adult of $L$. albescens and L. xylina of Okinawa, the thermal constant for males tended to be lower than for females, and the thermal threshold for males tended to be higher than for females (Table 4). Similar phenomena were reported for Planococcus kraunhiae (Arai, 1996), Galerucella nipponensis (Toda and Yano, 1986) and Megacopta punctissimum (Tayutivutikul and Yano, 1990). We think that the higher thermal constant for females than for males can be attributed to the difference in body size and to the cost of producing eggs.

The survival rates at $30.0^{\circ} \mathrm{C}$ tended to be lower than under other temperature conditions in $L$. albescens and L. xylina (Table 2). High mortality occurred in 1st and 6th instar larvae and pupae. Survival rates from egg to adult in tropical-subtropical species of Eurema and Catopsilia remained high up to $28^{\circ} \mathrm{C}$ (Jones et al., 1987). These data suggest that subtropical lepidopteran species are not resistant to temperatures higher than $30^{\circ} \mathrm{C}$.

Yeh et al. (2006) reported that the last-instar larvae of $L$. xylina $(n=30)$ were 5 th instar in males and 5th and 6th instars in females in the Bagua Mountain area of central Taiwan. We obtained 5th to 7th instars in males and 5th to 8th instars in females of L. xylina from Okinawa. Larval molts are different among the same sex in both regions, and are more diverse in Okinawan L. xylina.

Ficus microcarpa was recorded as a host plant of L. xylina in Taiwan (Chao, 1996), but not as a host plant of L. albescens (e.g. Schaefer et al., 1988) and L. xylina in Japan. We collected egg masses of 
L. albescens and L. xylina from F. microcarpa in Okinawa; therefore, F. microcarpa is probably also an additional host plant of $L$. albescens and $L$. xylina in Okinawa, but this remains to be confirmed.

\section{ACKNOWLEDGMENTS}

We thank Dr. Hirofumi Yamaguchi for providing valuable information on rearing Okinawan gypsy moths. We also thank Kazuki Ohnishi and Akihiko Igarashi for their help in collecting samples. We thank Dr. Paul Schaefer for the review.

\section{REFERENCES}

Arai, T. (1996) Temperature-dependent developmental rate of three mealybug species, Pseudococcus citriculus Green, Planococcus citri (Risso), and Planococcus kraunhiae (Kuwana) (Homoptera: Pseudococcidae) on citrus. Jpn. J. Appl. Entomol. Zool. 40: 25-34 (in Japanese).

Chang, Y. C. (1991) Integrated pest management of several forest defoliators in Taiwan. For. Ecol. Manage. 39: $65-72$.

Chao, J. T., P. W. Schaefer, Y. B. Fan and S. S. Lu (1996) Host plants and infestation of casuarinas tussock moth Lymantria xylina (Lepidoptera: Lymantriidae) in Taiwan. Taiwan J. For. Sci. 11: 23-28.

Furuta, K. (1973) Developmental zero temperature and effective thermal constant in Lymantria dispar collected from Sapporo, Hokkaido. Forest Pests 22: 120-123 (in Japanese).

Inoue, H. (1982) Lymantriidae. Moths of Japan Vol. 1. Text. (H. Inoue, S. Sugi, H. Kuroko, S. Moriuti and A. Kawabe, eds.). Kodansha, Tokyo, pp. 628-638 (in Japanese).

Jinbo, U. (2001) Insects of Nagashima collected in June 2000. Reports of the Chugoku-Shikoku Branch of the Ecological Society of Japan 59: 26-34 (in Japanese).

Jones, R. E., J. Rienks, L. Wilson, C. Lokker and T. Churchill
(1987) Temperature, development and surival in monophagous and polyphagous tropical pierid butterflies. Australian J. Zool. 35: 235-246.

Kiritani, K. (1997) The low development threshold temperature and the thermal constant in insects, mites and nematodes in Japan. Misc. Publ. Natl. Inst. Agro-Environ. Sci. 21: 1-72 (in Japanese).

Nasu, Y., Y. Arita, M. Kimura and A. Ogata (2004) Some Lepidopterous pests of eucalyptus trees from Japan. Jpn. J. Appl. Entomol. Zool. 48: 123-133 (in Japanese with English summary).

Pogue, M. G. and P. W. Schaefer (2007) A Review of Selected Species of Lymantria Hubner [1819] (Lepidoptera: Noctuidae: Lymantriinae) from Subtropical and Temperate Regions of Asia, Including the Descriptions of Three New Species, Some Potentially Invasive to North America. U. S. Dept. Agric., Forest Health Tech. Enterprise Team, Techn. Transfer FHTET. 223 pp.

Schaefer, P. W., K. Ikebe and Y. Higashiura (1988) Gypsy moth, Lymantria dispar (L.), and its natural enemies in the far east (especially Japan). Del. Agr. Exp. Sta. Bull. 476: $1-160$.

Tayutivutikul, J. and K. Yano (1990) Biology of insects associated with the Kudzu plant, Pueraria lobata (Leguminosae) 2. Megacopta punctissimum (Hemiptera, Plataspidae). Jpn. J. Entomol. 58: 533-539.

Toda, M. and K. Yano (1986) Life history of Galerucella nipponensis (Laboissiere) (Coleoptera: Chrysomelidae). Proc. Chugoku Branch Appl. Entomol. Zool. Soc. 28: 18-25 (in Japanese).

Tominaga, S. (2004) Host-plant of Lymantria dispar in Southern Okinawa-jima Is. Insects of Loochoos 24: 72 (in Japanese).

Yeh, S. T., C. T. Liao, C. C. Chen and W. F. Ko (2006) Biological characteristics of casuarinas moth Lymantria xylina (Lepidoptera: Lymantriidae) in Bagua mountain area. Bulletin of Taichung District Agricultural Improvement Station 93: 41-54. 